\title{
Role of Heme and Heme-Proteins in Trypanosomatid Essential Metabolic Pathways
}

\author{
Karina E. J. Tripodi, Simón M. Menendez Bravo, and Julia A. Cricco \\ Departamento de Química Biológica and Instituto de Biología Molecular y Celular de Rosario (IBR, CONICET-UNR), \\ Facultad de Ciencias Bioquímicas y Farmacéuticas, Universidad Nacional de Rosario, Suipacha 531, S2002LRK Rosario, Argentina
}

Correspondence should be addressed to Julia A. Cricco, cricco@ibr.gov.ar

Received 21 December 2010; Accepted 7 February 2011

Academic Editor: Claudio Alejandro Pereira

Copyright (๑) 2011 Karina E. J. Tripodi et al. This is an open access article distributed under the Creative Commons Attribution License, which permits unrestricted use, distribution, and reproduction in any medium, provided the original work is properly cited.

Around the world, trypanosomatids are known for being etiological agents of several highly disabling and often fatal diseases like Chagas disease (Trypanosoma cruzi), leishmaniasis (Leishmania spp.), and African trypanosomiasis (Trypanosoma brucei). Throughout their life cycle, they must cope with diverse environmental conditions, and the mechanisms involved in these processes are crucial for their survival. In this review, we describe the role of heme in several essential metabolic pathways of these protozoans. Notwithstanding trypanosomatids lack of the complete heme biosynthetic pathway, we focus our discussion in the metabolic role played for important heme-proteins, like cytochromes. Although several genes for different types of cytochromes, involved in mitochondrial respiration, polyunsaturated fatty acid metabolism, and sterol biosynthesis, are annotated at the Tritryp Genome Project, the encoded proteins have not yet been deeply studied. We pointed our attention into relevant aspects of these protein functions that are amenable to be considered for rational design of trypanocidal agents.

\section{Introduction}

Trypanosomes are parasitic protists that cause significant human and animal diseases worldwide [1], among which it is important to highlight the species relevant for human health, such as sleeping sickness or African trypanosomiasis (Trypanosoma brucei), Chagas' disease or American trypanosomiasis (Trypanosoma cruzi), and leishmaniasis (Leishmania spp.). The life cycle of these trypanosomatids is complex, presenting several developmental stages in different hosts. They have developed a digenetic life cycle with one or several vertebrate hosts and a hematophage insect vector that allows the transmission between them. A direct consequence is the environmental changes suffered among their life cycle thus, they have to adapt their metabolism to different nutrient availability [2]. Another feature of these parasites is the presence of nutritional requirements for several essential cofactors where heme is included. They totally or partially lack the heme biosynthetic pathway (revisited by Kořený et al. [3]). Heme plays a fundamental role in many cellular processes. It is an essential cofactor for proteins involved in oxygen transport and storage (hemoglobin and myoglobin), mitochondrial electron transport (Complex II-IV), drug and steroid metabolism (cytochromes), signal transduction (nitric oxide synthases, soluble guanylate cyclases), and transcription and regulation of antioxidantdefense enzymes. Heme is also a regulatory molecule; its cytosolic to nuclear ratio and the absolute amount of its concentration affects gene transcription and translation; thus, the intracellular heme level must be tightly regulated $[4,5]$. Hence, these trypanosomatids are dependent on the uptake of this compound from their hosts. After being imported, heme is transported and inserted into target heme-proteins, which are distributed throughout different subcellular compartments. It is not well understood how these organisms acquire heme and how this cofactor is distributed inside the cell. However, they contain hemeproteins-like cytochromes, involved in essential metabolic pathways. This review will be focused in the presence and role of relevant heme-proteins in trypanosomatids. 


\section{Heme General Features}

Heme is an essential molecule for most archaea, bacteria, and eukaryotes. Moreover, since the growth of bacteria and plants rely on the correct formation of tetrapyrroles, their corresponding biosynthetic pathways are attractive targets for antibacterial drug development and herbicide treatment [7-9]. The free living nematode Caenorhabditis elegans lacks the complete heme biosynthetic pathway; it feeds on bacteria and thus has easy access to heme [10]. On the other hand, Plasmodium falciparum, which has access to the host's abundant heme reservoir, is clearly dependent on its own intrinsic heme biosynthesis $[9,11]$.

The heme compounds are iron-coordinated porphyrins, specifically protoporphyrin IX (PPIX). The iron at the center of the tetrapyrrol ring can adopt the oxidized ferric $\left(\mathrm{Fe}^{+3}\right)$ or the reduced ferrous $\left(\mathrm{Fe}^{+2}\right)$ oxidation states. The majority of the porphyrins contain iron as the central metal ion. The most abundant heme is heme B (or protoheme), and it is found in nearly all the heme-proteins such as hemoglobin, myoglobin, and so forth. The tetrapyrrol structure of heme B contains two propionate, two vinyl and four methyl side chains (Figure 1). The oxidation of the methyl side chain to a formyl group and the substitution of a vinyl side chain with a 17-carbon isoprenoid side chain convert heme $B$ into heme $\mathrm{A}$, the prosthetic group of the mitochondrial cytochrome $c$ oxidase and of the several bacterial terminal oxidase. $C$-type hemoproteins, such as cytochrome $c$ and $b c 1$ complex, contain heme $c$ in which the two vinyl side chains of the heme B are covalently attached to the protein (Figure 1). For almost all organisms, hemes are essential components of their energy recovering electron transport chains and cofactors for several proteins. Many enzymes like peroxidases, catalases, and the large group of cytochrome P450 also rely on heme as a prosthetic group. Heme-proteins can furthermore serve as sensors for diatomic gases such as $\mathrm{O}_{2}, \mathrm{CO}$, and $\mathrm{NO}$ and for $\mathrm{CO}_{2}$ in signal transduction pathways [4].

2.1. Heme Biosynthesis. The heme biosynthetic pathway is highly conserved through evolution $[3,12]$. It is present in most organisms but differs in the synthesis of the first precursor, delta-aminolevulinic acid (ALA). All prokaryotes (with the exception of $\alpha$-proteobacteria) and photosynthetic eukaryotes synthesize ALA via three consecutive enzymatic steps starting with glutamate. The $\alpha$-proteobacteria and most nonphotosynthetic eukaryotes synthesize ALA by the condensation of glycine with succinyl-CoA using the single ALA-synthase enzyme (ALAS). The remaining seven steps of the pathway (from ALA to heme B) are carried out by the same enzymes in all organisms $[12,13]$.

Eukaryotes differ also in the intracellular localization of individual enzymatic steps. The photosynthetic eukaryotes synthesize heme exclusively in the chloroplasts, while in most heterotrophic eukaryotes the pathway is split between the mitochondrion and cytosol [12] (Figure 1). An interesting case is the apicomplexan parasite because its heme synthesis starts in the mitochondrion, then ALA is transported to the apicoplast and the subsequent steps take place in this specialized organelle, but the last steps appear to proceed in the mitochondrion $[14,15]$.

Iron and porphyrins are highly toxic to cells, and heme per se is a cytotoxic macrocycle with peroxidase activity. The level of free heme inside the cell is maintained very low, and there is a tight control of its biosynthesis based on cellular requirements. The damaging effect of heme excess is due to iron-induced pro-oxidant effect on DNA, proteins, membrane lipids, and the cytoskeleton. The elevated level of noniron porphyrins has been linked to harmful effects; they accumulate in membranes and can cause cellular damage $[5,16]$.

2.2. Heme in Trypanosomatids. Most of the eukaryotic organisms are able to synthesize heme and organisms with deficiency in this pathway are not common. Some examples are the anaerobic protists such as Giardia, Trichomonas, and Entamoeba. They possess a rudimentary mitochondria-like organelle called hydrogenosome or mitosome [18]. These protists do not generate energy by oxidative phosphorylation, thus they do not have cytochromes and respiratory chains. Furthermore, heme-proteins involved in oxidative metabolism such as oxidases, peroxidases, catalases, and hydroxylases are not needed in anaerobic conditions and consequently they do not require heme as a cofactor [19]. But there are other organisms that even when they depend on oxidative phosphorylation, are defective in the synthesis of heme. Some examples are a tick [20]; a filarial nematode [21], the free-living nematode C. elegans [10] and even most of the kinetoplastid parasites also belong to this category. These organisms can afford their deficiency in heme synthesis due to an easy access to this compound from their environment [21-23].

In a recently published work, Kořený and coworkers [3] discuss from a phylogenetic point of view the absence of a complete heme biosynthetic pathway in Kinetoplastid flagellate organisms. These represent an interesting group of species, where some of them lack of the complete pathway while others possess only the last three biosynthetic steps. The authors propose a scenario in which the ancestor of all trypanosomatids was completely deficient in the heme synthesis. In some trypanosomatids, with the exception of the genus Trypanosoma, the pathway was partially rescued by genes encoding enzymes for the last three steps supposedly obtained by horizontal transfer. On the other hand, the trypanosomes have remained fully deficient of heme synthesis and obtain this compound from their hosts ([3] and references cited therein). In particular, the absence of the complete heme biosynthetic pathway in T. cruzi has been pointed out by biochemical studies $[24,25]$. Later, the absence of the genes for the enzymes involved in heme biosynthesis in the genomes of T. cruzi and T. brucei was corroborated when the TriTryp genomic sequence project was completed $[26,27]$ (TriTrypDB, http://tritrypdb.org/tritrypdb/ [28]). The in vitro cultivation of the mentioned Trypanosoma requires the addition of heme compounds in the form of hemoglobin, hematin, or hemin to the medium $[29,30]$. Several other trypanosomatids including Leishmania spp. and Crithidia fasciculata can grow in media in which hemin 


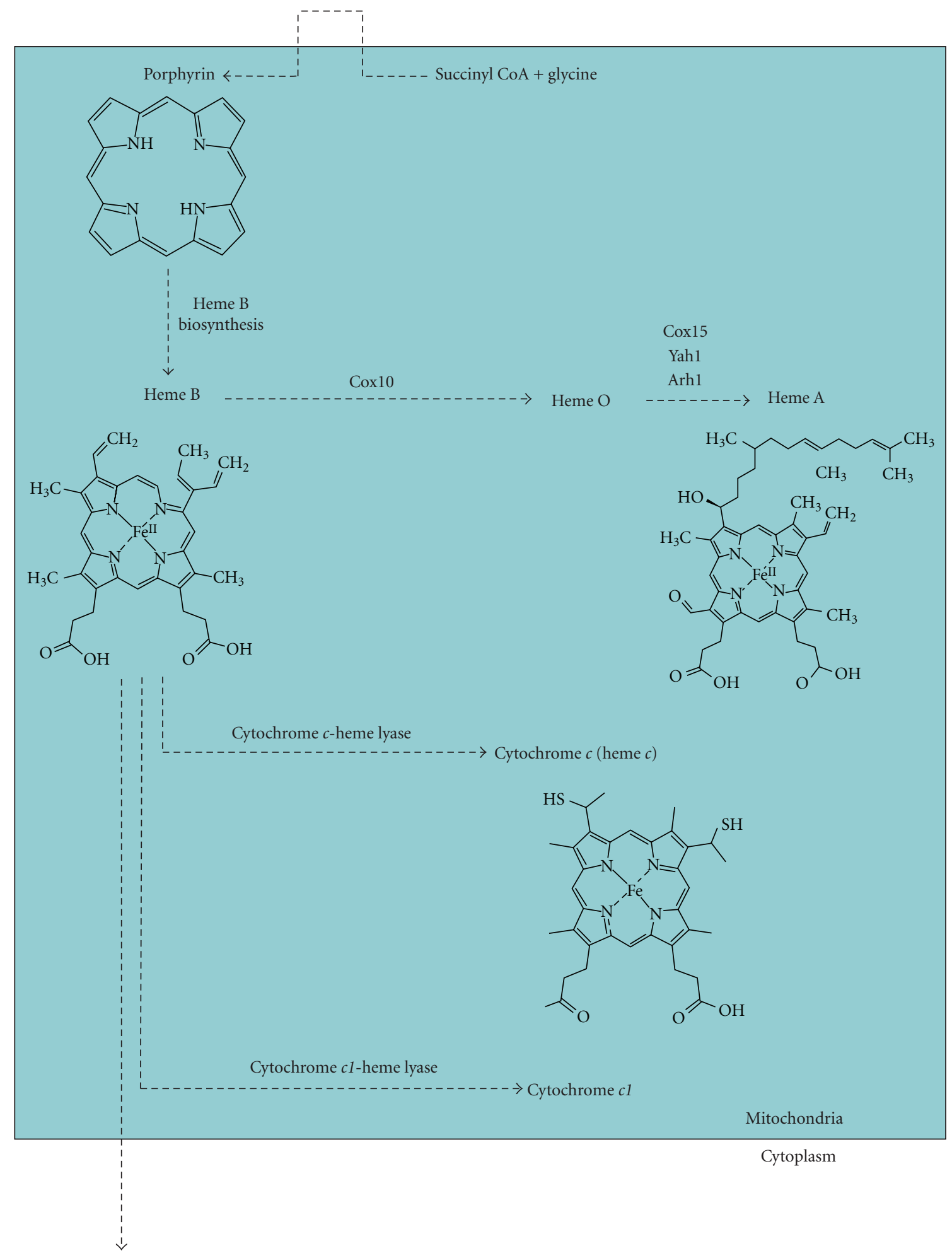

Hemoglobin

Figure 1: Schematic view of different hemes biosynthesis pathways in S. cerevisiae. Adapted from Moraes et al. [6]. 


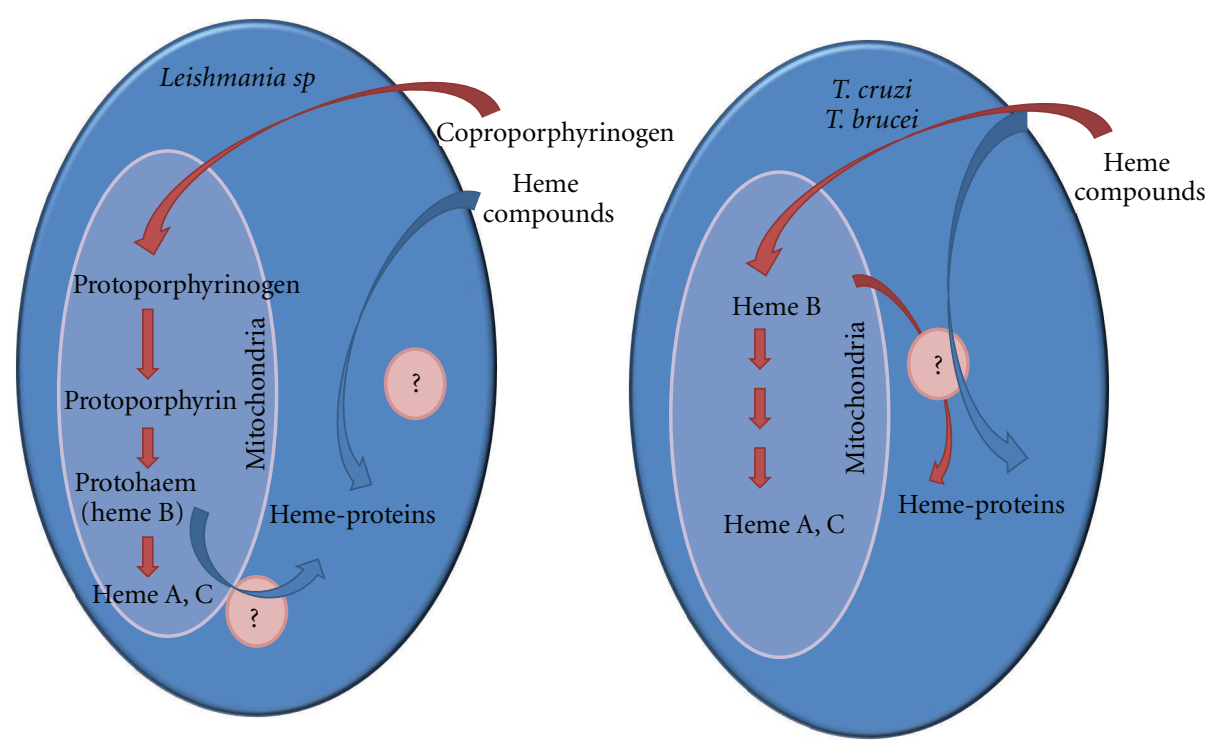

FIgURE 2: Heme biosynthesis in trypanosomatids (revisited by Kořený et al. [3]). Leishmania spp. can perform the last three steps in heme synthesis, catalyzed by coproporphyrinogen oxidase, protoporphyrinogen oxidase, and ferrochelatase, localized into the mitochondria. $T$. cruzi and T. brucei cannot perform any step for heme B biosynthesis and must import heme compounds (hemoglobin, hemin, etc.) from their hosts. They can modify heme B to obtain heme A and cytochrome $c$, although this has been described only for T. cruzi, it is probable that L. major and T. brucei have the same capability. Mechanisms by which these trypanosomatids couple heme to apoproteins or regulate heme compounds levels to avoid toxic effects are unknown.

is replaced by protoporphyrin IX [30-32]. This observation provides indirect evidence that at least the last enzyme of the pathway (ferrochelatase) remains functional. There are other experimental data that support that Leishmania spp. presents a partial pathway for heme biosynthesis, $[31,33,34]$.

The evidence mentioned above indicates that medical relevant trypanosomes are completely (T. cruzi and T. brucei) or partially (Leishmania spp.) deficient in heme synthesis, as it is resumed in Figure 2, and they must therefore scavenge this molecule from their hosts. Once heme is imported, it has to be distributed inside the cell and inserted into the target heme-proteins. As heme is a highly toxic molecule, it is well accepted that heme carriers or chaperons involved in its distribution exist. But, in eukaryotic cells, these type of proteins were not reported yet [35] and the processes of heme transport and distribution in trypanosomatids remain unknown. Besides, these parasites present heme-proteins involved in essential metabolic pathways like biosynthesis of sterols and polyunsaturated fatty acids (PUFAs) carried out in the endoplasmic reticulum (ER) and respiratory complexes in the mitochondrion, as it is shown in Figure 3. The understanding of how they import, distribute, utilize heme, and assemble heme-proteins can help to elucidate the essential metabolic pathway in these trypanosomatids.

\section{Heme and Biosynthesis of Polyunsaturated Fatty Acids and Sterols are Connected through Cytochromes}

The precise role of heme in the proliferation as well as differentiation of these parasites remains unknown. In the next section, we will focus our discussion on cytochromes and their role in lipid biosynthesis. These heme-proteins have been scarcely studied in trypanosomatids, in spite of being involved in a variety of key pathways. The Table 1 shows a list of genes that were annotated as cytochromes $b 5, c$, and $\mathrm{P} 450$ in the TriTrypDB, most of them assigned by comparison of sequences but without biochemical evidence.

\subsection{Cytochrome b5: A Crucial Piece in the Fatty Acid Desatu-} ration Reaction. Fatty acid biosynthesis in trypanosomatids has gained attention in the last few years, since endogenous production of these compounds seems to be essential for the parasite life cycle. A few years ago, the complete pathway for polyunsaturated fatty acid (PUFA) synthesis in trypanosomatids was described $[39,40]$. Indeed, it was established that whereas L. major is able to obtain docosahexaenoic acid (DHA, 22:6) and docosapentaenoic acid (DPA, 22:5) from oleate, trypanosomes cannot perform this process. As Leishmania, they produce oleate de novo, but they have to import precursors from the hosts in order to generate DHA and DPA. The enzymes involved in PUFAs biosynthesis are elongases and the so-called "front end" desaturases.

A common feature of all fatty acid desaturases is the requirement of an electron donor, ferredoxin in plastids and bacteria, and cytochrome $b 5$ (cytb5) in endoplasmic reticulum [36]. In fact, cytb5 is needed not only for the successful desaturation of fatty acids, but also for many other oxidative reactions in the cell. It is a small hemebinding protein that acts as an electron-transfer component in the desaturation reaction [41], with two possible modes of action. In the first one, desaturation can be carried out by a 


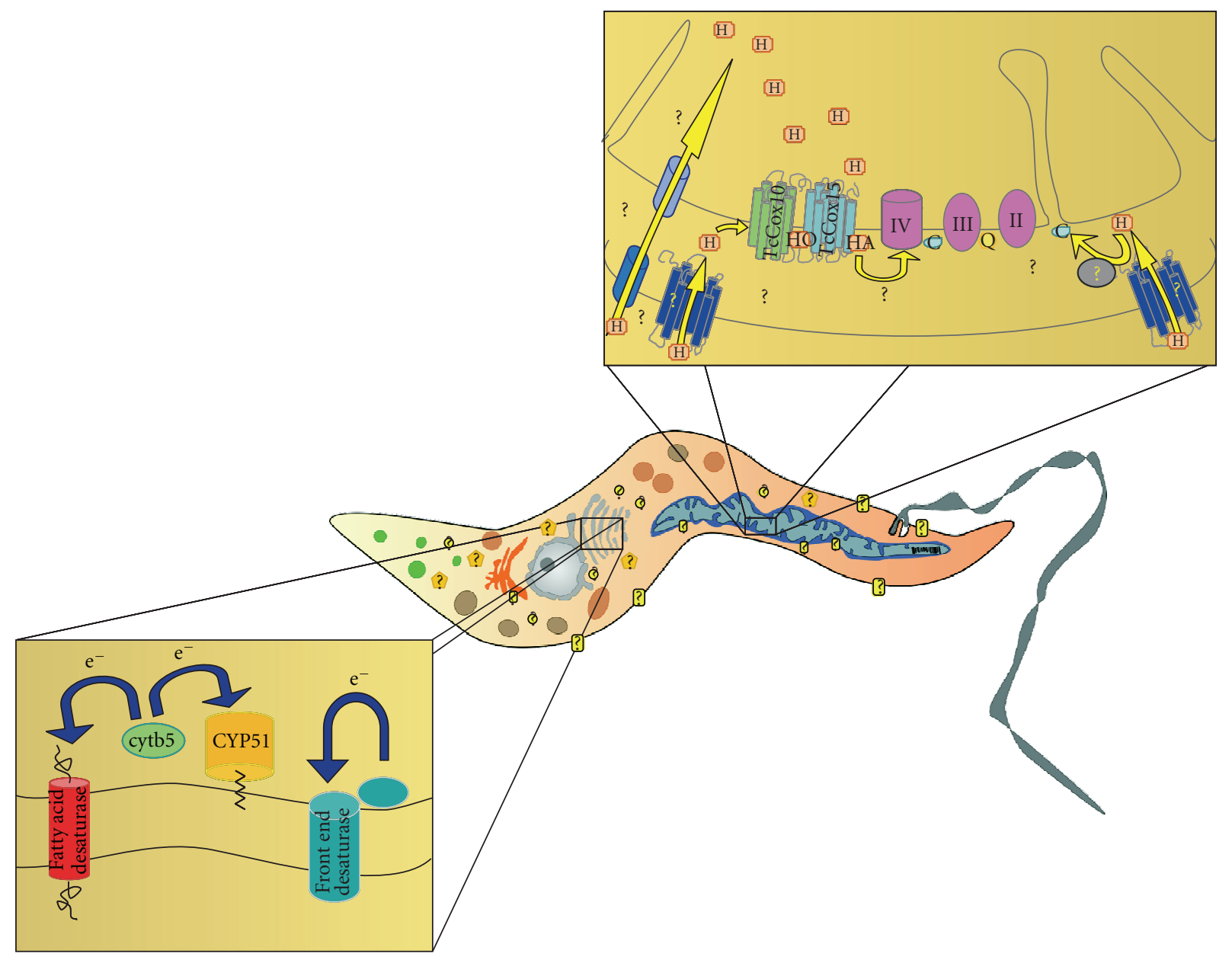

FIGURE 3: Schematic representation of transport, trafficking, and uses of heme in a trypanosomatid epimastigote. The amplified areas correspond to the mitochondrial and endoplasmic reticulum regions (above and below resp.) where the heme-proteins mentioned in the text are located. In the mitochondrion, heme B is internalized by one or several unknown transport systems. Once in the matrix (or alternatively in the intermembrane space) heme $\mathrm{B}$ is transformed into heme $\mathrm{O}$ by the membrane-bound heme $\mathrm{O}$ synthase (Cox10) enzyme, and immediately later heme $\mathrm{O}$ is converted into heme A by the heme A synthase (Cox15) enzyme [17]. Finally heme A is incorporated into the cytochrome $c$ oxidase complex by an unknown mechanism. In the endoplasmic reticulum cytochrome $b 5$ takes electrons from several donors, such as NADH, FADH, and other reduced compounds (not shown), and serves in turn as an electron donor for the various transmembrane fatty acid desaturases and other ER proteins such as CYP51. Alternatively, front-end desaturases contain a cytochrome-type domain which serves as their own electron donor. See text for more details. Abbreviations: H: heme B; HA: heme A; HO: heme O; C: $c$-type cytochrome; Q: quinone; II, III, IV: complexes II, III, and IV of the electron transport chain, respectively.

multienzymatic system, which is composed by a desaturase, NADH cytochrome $b 5$ reductase and cyt $b 5$. The membranebound cyt $b 5$ transfers electrons by lateral diffusion, from NADH cytochrome $b 5$ reductase to the desaturase [42]. In a second mode, desaturases are modular proteins that include a cyt $b 5$ domain as a fusion either on the N-terminus in the case of "front end" desaturases $[36,43]$ or on the C-terminus in the case of fungal $\Delta 9$-desaturases [44, 45]. In addition to the desaturases, cytb5 domains have been found in a number of unrelated proteins, such as nitrate reductases, sulfite oxidases, and L-lactate dehydrogenases [45].

Desaturases may be classified as type I, II, or III [36]; as they introduce double bonds in the middle of the carbon chain (I), near the methyl-end (II), or at the carboxy (front)-end (III). As mentioned above, all of them require an electron donor, which is cytb5 in all trypanosomatids. However, for type I and II desaturases, cytb5 acts as an enzyme-independent component of an electron transfer chain (with exception of fungal $\Delta 9$-desaturases); whereas type III desaturases have these activities as a domain in the $\mathrm{N}$-terminus. In trypanosomatids, we found the three types of desaturases, but a different route for PUFAs biosynthesis operates in L. major and in trypanosomes (Figure 4). $L$. major contains $\Delta 9, \Delta 12, \omega 3, \Delta 4, \Delta 5$, and $\Delta 6$-desaturases ( $\Delta 9$ Des, $\Delta 12$ Des, $\omega 3$ Des, $\Delta 4$ Des, $\Delta 5$ Des and $\Delta 6$ Des), whereas T. cruzi and $T$. brucei only contain $\Delta 9, \Delta 12$ and $\Delta 4$ desaturases ( $\Delta 9$ Des, $\Delta 12$ Des and $\Delta 4$ Des). They are enzymes 
TABLE 1: Cytochrome genes present in L. major, T.cruzi and T. brucei. Most of the genes were annotated by similarity in Gene Bank and were published within the TriTryp Genome Project. Only a few of them have been submitted to cloning and characterization.

\begin{tabular}{|c|c|c|c|}
\hline $\begin{array}{l}\text { Type of } \\
\text { cytochromes }\end{array}$ & Organism & Genes & References \\
\hline \multirow{3}{*}{ Cytb5 } & L. major & $\begin{array}{l}\text { LmjF11.0580, LmjF09.1490, LmjF36.4675, } \\
\text { LmjF07.0810, LmjF09.1500 (pseudogene) }\end{array}$ & Ivens [34] \\
\hline & T. brucei & $\begin{array}{l}\text { Tb927.3.3470, Tb927.7.520, } \\
\text { Tb11.02.4485,Tb11.01.5225 }\end{array}$ & $\begin{array}{l}\text { Berriman et al. } \\
{[26]}\end{array}$ \\
\hline & T. cruzi & $\begin{array}{l}\text { Tc00.1047053504431.109, Tc00.1047053508799.160, } \\
\text { Tc00.1047053506773.44, Tc00.1047053507951.154, } \\
\text { Tc00.1047053503653.60, Tc00.1047053510355.269, } \\
\text { Tc00.1047053509395.100, Tc00.1047053506753.110 }\end{array}$ & El-Sayed et al. [27] \\
\hline \multirow{3}{*}{ Cytc } & L. major & LmjF16.1320, LmjF16.1310 & Ivens [34] \\
\hline & T. brucei & Tb927.8.1890, Tb927.8.5120 & $\begin{array}{l}\text { Berriman et al. } \\
{[26]}\end{array}$ \\
\hline & T. cruzi & $\begin{array}{c}\text { Tc00.1047053511391.160, Tc00.1047053508959.4, } \\
\text { Tc00.1047053506949.50 }\end{array}$ & El-Sayed et al. [27] \\
\hline \multirow{3}{*}{ CytP450 } & L. major & $\begin{array}{l}\text { LmjF27.0090, LmjF30.3550, } \\
\text { LmjF34.3330LmjF11.1100 (lanosterol } 14 \alpha \text { demetilase, } \\
\text { putative) }\end{array}$ & Ivens [34] \\
\hline & T. brucei & $\begin{array}{l}\text { Tb927.3.680, Tb11.02.4080 (lanosterol } 14 \alpha \\
\text { demetilase, putative) }\end{array}$ & $\begin{array}{l}\text { Joubert et al. [37], } \\
\text { Berriman et al. } \\
{[26]}\end{array}$ \\
\hline & T. cruzi & $\begin{array}{l}\text { Tc00.1047053509719.40, Tc00.1047053509231.10, } \\
\text { Tc00.1047053510101.50, Tc00.1047053506297.260 } \\
\text { (lanosterol 14-alpha-demethylase, putative) }\end{array}$ & $\begin{array}{l}\text { El-Sayed et al. [27] } \\
\text { Buckner et al. [38] }\end{array}$ \\
\hline
\end{tabular}

from the endoplasmic reticulum, with four or six transmembrane segments, as described for mouse $\Delta 9$ Des [46] and $\triangle 6$ Des from Bacillus subtilis [47].

It is known that PUFAs accumulate at higher levels in the parasite than in the vertebrate hosts. This behavior could be reflecting a requirement for more fluid membranes in order to face with different growth environment and/or to be fully infective. In addition, the presence of linoleate seems to be crucial for both procyclic and bloodstream form of $T$. brucei, as was formerly seen for epimastigotes of T. cruzi [48]. In a recent report, linoleate synthesis was blocked by either inhibition or RNA interference of oleate desaturase (OD, a $\Delta 12$ Des), causing a dramatic drop in parasite growth [49]. This result and the fact that mammals lack OD validate this enzyme as a chemotherapeutic goal. Other potential targets are "front end" desaturases since there is no evidence for the presence of $\Delta 4$-Des in mammals. However, the relevance of these enzymes in the life cycle of these parasites awaits further research.

3.2. Cytochrome P450 and Its Role in Sterol Biosynthesis. The sterols of trypanosomatids resemble those of fungi, both in composition and biosynthesis. An important step in the synthesis of ergosterol, an essential component of parasite membranes, is carried out by CYP51. This enzyme belongs to the cytochrome P450 (cytP450) superfamily and is a sterol14 - $\alpha$-demethylase that performs the oxidative removal of 14-alpha methyl group in lanosterol. It is localized in the endoplasmic reticulum, probably associated by a stretch of hydrophobic residues. CytP450 are mixed function oxidases that catalyze the oxidation of a number of substrates. In the case of CYP51, it has been described that it accepts electrons from NADPH-cytP450 reductase (CPR) and from cytb5. The role of cytb5 is to enhance the efficiency of the CYP51 reaction by assisting the interaction and electron transfer between CPR and CYP51 [41].

T. cruzi and Leishmania synthesize ergosterol at all life stages, while the bloodstream form of T. brucei is able to import cholesterol from the host. Before the conclusion of the Trypanosomatids Genome Project, an enzyme with sterol-14- $\alpha$-demethylase activity from $T$. bruce $i$ was cloned and characterized by complementation assays in the erg11 yeast mutant cells [37]. A few years later, two alleles with 99\% of identity were identified in T. cruzi, and they were $83 \%$ identical to the T. brucei protein [38]. Meanwhile, in Leishmania there is a gene annotated as a putative lanosterol 14- $\alpha$-demethylase (LmjF11.1100) that has not been characterized yet.

A number of antifungal azoles, inhibitors of ergosterol biosynthesis by binding to CYP51, have been experienced in protozoan parasites with some success. Nevertheless, the modification of azoles to enhance the efficiency and circumvent the potential drug resistance has been problematic due to the lack of structural insights into the drug binding site. Recently, the resolution of the crystal structure of T. cruzi and T. brucei CYP51 cocrystallized with inhibitors (fuconazole or posaconazole) released the opportunity to develop rationally designed anti-trypanocidal drugs [50]. Another work, 
PUFAs biosynthesis in trypanosomatids

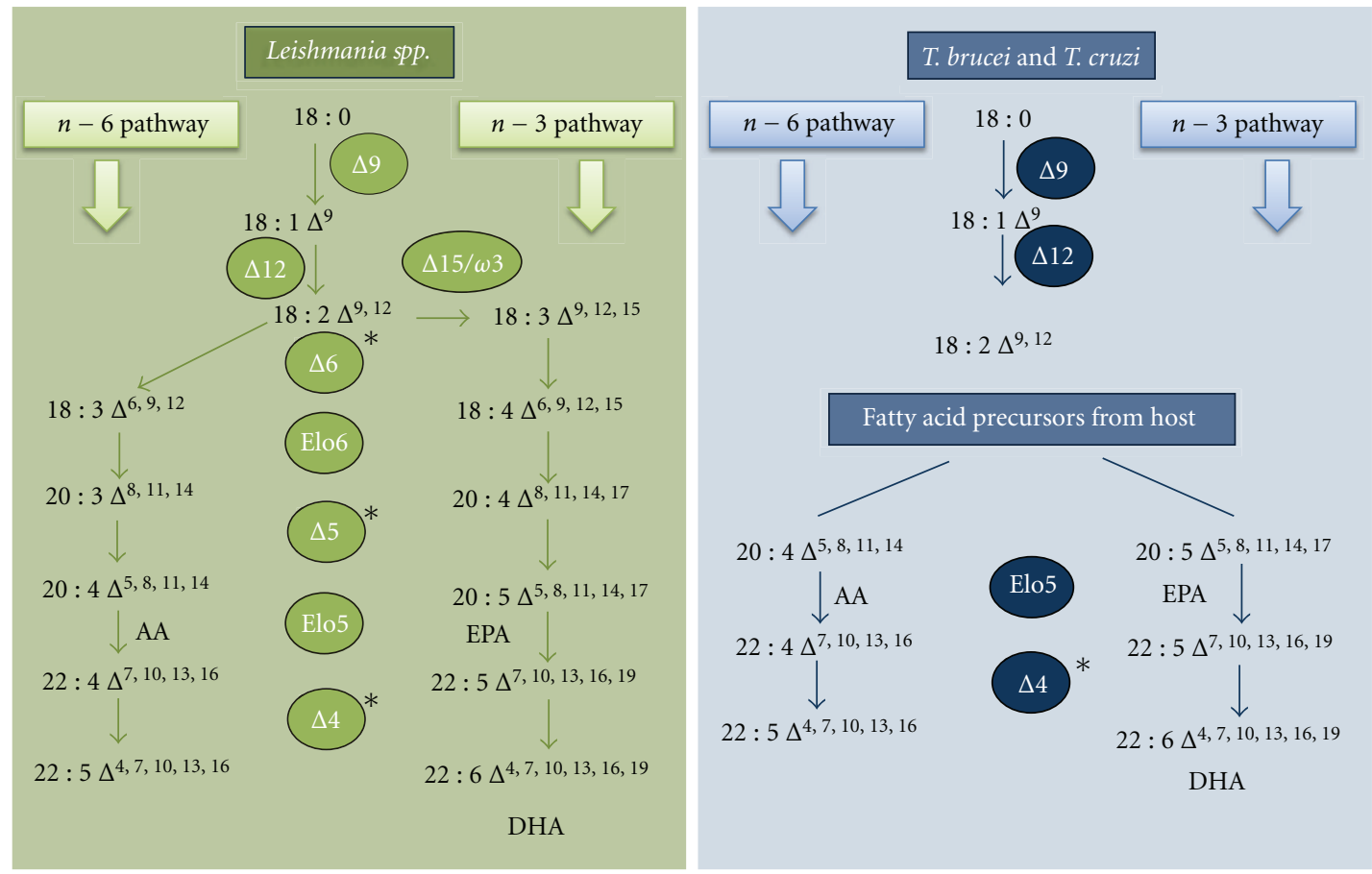

FIGURE 4: Biosynthesis of polyunsaturated fatty acids in trypanosomatids. This is an important pathway that takes place in trypanosomatids and has been recently described $[39,40]$. Cytochrome $b 5$ operates as the electron donor for desaturation, both as an independent enzyme or as a domain at the $\mathrm{N}$-terminus of the desaturase (wildcards). $\Delta 12, \Delta 15(\omega 3)$ and $\Delta 4$-desaturases are absent from mammalian hosts and are potential targets for trypanocidal agents.

that analyze the binding properties of a CYP51 inhibitors library by X-ray techniques, revealed that the $\mathrm{N}$-[4-pyridyl]formamide scaffold group binds in the active site of the enzyme via conserved residues and the heme prosthetic group. The use of one of these nonazole inhibitors in a mouse model of T. cruzi acute infection triggered the breakdown of membrane parasites and the death of amastigotes [51].

\section{Heme in the Mitochondrion}

The mitochondria are one of the most relevant heme-protein containing organelles, and it includes the respiratory chain complexes. A characteristic of these parasites is their single and usually well-developed mitochondrion, which presents functional and structural changes depending on the stages of its life cycle [52]. In this part of the review, we describe all the data available about mitochondrial heme and cytochromes in trypanosomatids, highlighting the similitude and differences compared to other organisms.

4.1. Cytochrome $c$ in Trypanosomatids - A Novel Pathway for Cytochrome c Maturation. All eukaryotes, and almost all prokaryotes, that use oxygen as the terminal electron acceptor in the respiratory chain possess cytochromes $c$ and $c 1$ (cytc and cytc1). The principal physiological role of mitochondrial cytc and cytcl is the electron transfer during oxidative phosphorylation. These $c$-type cytochromes are distinguished from other types ( $a$ and $b$ ) because heme is covalently attached to the polypeptide via thioether bonds. In the vast majority of the cases, heme is attached to the protein by two thioether bonds between the heme vinyl groups and the thiol of cysteine residues in a $\mathrm{CXXCH}$ motif (heme-binding motif) (Figure 1). There are, however, a few exceptions. One is the termed pseudo-c-type cytochrome center in the cytochrome bf complex of thylakoids where a fourth heme is attached to the cytochrome $b$ polypeptide by a novel single-thioether bond [53, 54]. Also, in species from the phylum Euglenozoa, which include the medical relevant trypanosomatids (T. brucei, T. cruzi, and pathogenic Leishmania spp.), heme is uniquely attached to the mitochondrial $c$-type cytochromes by a single-thioether bond within a F/AXXCH heme binding motif $[55,56]$.

The cytochrome $c$ maturation process involves the covalent attachment of heme to the apocytochrome polypeptide. Depending on the mechanism and the enzymes employed for this posttranslational modification, the $c$-type cytochromescontaining organisms are classified into five distinct groups (Table 2).

The system I, also known as the Ccm system (for cytochrome $\underline{c}$ maturation system), is found in $\alpha$ - and $\gamma$-proteobacteria, deinococci, and mitochondria of some plants and protozoa [57]. This is well understood in Escherichia coli $[58,59]$, and it is the most complex system. It consists of eight essential proteins, named $\mathrm{CcmA}-\mathrm{H}$, and a number of 
TABle 2: Different $c$-type cytochromes maturation systems and examples of organisms which possess each one (in the case of eukaryotic organisms is also denoted the organelle where the system operates) [59,63].

\begin{tabular}{lllll}
\hline System I & System II & System III & System IV & System V \\
\hline E. coli & & Yeast & C. reinhardtii & T. cruzi \\
Pseudomonas & B. subtilis & Neurospora & B. subtillis (In some & T. Brucei \\
Rhizobium & Mycobacterium tuberculosis & C. elegans & oxygenic & Leishmania spp. \\
Rhodobacter & Helicobacter pylori & Mouse & phototrophic bacteria & C. fasciculata \\
Paracocus & Synechocystis & Human & and several Bacillus & Euglena gracilis \\
& & Mitochondria & Mitochondria \\
Plant/Protozoa & Plant Chloroplasts & & & \\
Mitochondria & & & \\
\hline
\end{tabular}

accessory proteins. CcmA-H are all membrane anchored or integral membrane proteins. Heme attachment occurs in the periplasm, after the separate translocation of heme and the polypeptide across the plasma membrane, both synthesized in the cytoplasm [60-62].

The system II is less understood than system I, and it is the responsible for the assembly of the most complex $c$-type cytochromes in which there are multiple hemes per polypeptide chain (bacterial cytochromes). This second system is present in Gram positive bacteria, cyanobacteria, and some $\beta$-, $\delta$-, and $\varepsilon$-proteobacteria, but also in plant and algal chloroplasts and possibly in archea. The proteins from system II do not share extensive sequence similarities with representatives of system I. The system II model organism is B. subtilis, and four proteins, ResA-C and CcdA, are associated to it [64].

The system III for cytochrome $c$ maturation is found only in the mitochondrial intermembrane space of some protists, fungi and animals and the enzymes involved are heme lyases. There are separate lyases for the attachment of heme to cytc and cytc1 [65].

The system IV has been described for the heme linkage to cytochromes of the $b f$ complex from oxygenic phototrophic bacteria and $b c$ complex in several Bacillus species $[53,66]$. Four genes in Chlamydomonas reinhardtii, a green alga, have been implicated in the covalent heme attachment to cytochrome bf complex (associated to system IV) [62].

The scenario for cytochrome $c$ maturation in the protist phylum Euglenozoa seems to be totally different from the aforementioned systems. They contain $c$-type cytochromes with a single covalent bound to the polypeptide chain through the cysteine in the F/AXXCH motif $[55,56,67]$.

The trypanosomatids possess cyt $c$ and $c y t c 1$, but there are no recognizable proteins belonging to the $c$-type cytochrome maturation systems, suggesting the presence of a distinct mitochondrial pathway. The X-ray crystal structure of cytc from the trypanosomatid Crithidia fasciculata was solved [68]. It revealed that the protein folding was remarkably similar to that of typical $(\mathrm{CXXCH})$ mitochondrial cytc (in this case cytc from yeast), including the stereochemistry of the covalent heme attachment to the protein. The difference appeared only in the missing thioether bond in the heme attachment site. However, S. cerevisiae cytc heme lyase cannot efficiently mature T. brucei cytc (containing an AAQCH heme binding motif), or a $\mathrm{CXXCH}$ variant, when they were expressed in the cytoplasm of E. coli [68]. The later results let the authors propose that a novel, yet unidentified, apparatus for maturation of cytc operates in trypanosomatids [68]. Why the T. brucei CXXCH mutant was not able to be maturated by the lyase (system III) is not fully clear.

Analysis of all the available genome sequences and all publicly accessible expressed sequence tag (EST) collections using BLAST reveal that single-cysteine attachment of heme to mitochondrial cytc remains as a unique characteristic to species from the phylum Euglenozoa [63]. In this scenario, this novel system is a good candidate to be validated as a possible target for drug design against pathogenic trypanosomatids, in addition to expanding our understanding about the biogenesis of heme-containing proteins.

4.2. Heme A Biosynthesis. Heme A is the essential cofactor only for the cytochrome $c$ oxidases $(\mathrm{CcO}$, Complex IV of the eukaryotic mitochondrial respiratory chain). It is synthesized from heme $B$ through two enzymatic steps catalyzed by the heme $\mathrm{O}$ synthase (HOS) or Cox10 and heme A synthase (HAS) or Cox15 enzymes (Figure 1) [69]. In eukaryotic cells, the heme A biosynthesis is carried out in the mitochondria, and HOS and HAS are integral mitochondrial inner membrane proteins [70, 71]. After heme A is synthesized, it is inserted into the subunit I of $\mathrm{CcO}$. Defects in the maturation of heme groups that are part of the oxidative phosphorylation system are also recognized as important causes of diseases $[6,72,73]$. In the same way, changes in mitochondrial heme A levels have been related to Alzheimer's disease [74, 75].

The presence of an active mitochondrial respiratory chain has been demonstrated in trypanosomatids but its metabolic dependence varies between them [52]. The bloodstream form of $T$. brucei shows a rudimentary mitochondrion with the activity of an alternative oxidase and welldeveloped glycosomes. In this case, the energetic metabolism depends primarily on glycolysis. But the procyclic form of $T$. brucei presents a well-developed mitochondrion and less glycosomal activity $[52,76]$. In T. cruzi, there is no evidence of a mitochondrial alternative oxidase activity, and it is proposed that this trypanosomatid depends on the respiratory chain activity throughout the complete life cycle. The presence of electron transport from complex II 
to complex IV has been demonstrated, but the contribution of complex I (NADH:ubiquinone oxidoreductase) to energy metabolism remains controversial [77, 78].

Biochemical studies developed in T. cruzi epimastigotes showed that the main terminal oxidase is the aa3 type [79], the canonical $\mathrm{CcO}$ for eukaryotic cells. Additionally, proteomic studies demonstrated the presence of subunits of complex IV $(\mathrm{CcO})$, other components of the respiratory chain and subunits of the FoF1 ATPase (complex V) [80, 81].

Based on the evidence about the peculiar biogenesis of cytc in trypanosomatids (discussed above), it was expected a possible particular mechanism of heme A biosynthesis in these organisms. However, in a recently published work by Buchensky et al. [17], the first functional characterization of T. cruzi ORFs that encoded for enzymes involved in heme A biosynthesis (named TcCox10 and TcCox15) was presented. The sequences of these putative proteins are conserved in others trypanosomatids. The authors showed that the T. cruzi Cox 10 and Cox 15 proteins were recognized by the yeast mitochondrial importing machinery, even though the mitochondrial targeting sequences reported for trypanosomatids are shorter than the ones in other cells, including yeast [82]. These T. cruzi proteins were fully active in the yeast mitochondria. Furthermore, the genes encoding TcCox10 and TcCox15 (TcCOX10 and TcCOX15) were differentially transcribed during the parasite life cycle. The authors postulate that the observed changes in the mRNA levels of TcCOX10 and TcCOX15 could be a form of regulation reflecting differences in respiratory requirements at different life stages.

It is important to note that, once heme is in the mitochondrion, it could be inserted in different mitochondrial heme-proteins. How heme is transported to the mitochondrion and how it is imported by the mitochondrial membranes to be used in this organelle are still open questions, since carriers, chaperons, and transporters have not been identified yet. Based on the evidences discussed here, while cytochrome $c$ biogenesis could proceed from a novel and characteristic mechanism, apparently restricted to Euglenophyta, the heme A biosynthesis might be synthesized by conserved enzymatic pathways.

\section{Concluding Remarks}

Trypanosomatids are under varying nutritional pressures during their life cycles; consequently, they must adapt their metabolism to different environments. These parasites display auxotrophies for various cofactors, including heme. Heme biosynthesis is absent from trypanosomes, and although L. major possesses the last three enzymes of the pathway, it still needs to import precursors from the host. From what we know up to now, a few points in which differences between parasites and hosts might be exploited for rational design of therapeutic compounds exist, for instance, the novel system for maturation of cytochromes $c$, which does not match to any other known system, and the role of cytochromes $b 5$ as electron donors in at least two essential pathways (PUFAs and ergosterol biosynthesis).
However, in spite of the conclusion of the genome project for TriTryp, there are a number of unknown aspects that need further research. It is not clear, for example, how heme group is internalized into the cell and how it is coupled to hemeproteins. Also it is not known how different cytochromes reach their final intracellular location: mitochondria (cytc) and endoplasmic reticulum (cytb5, CYP51) and how cytb5 is organized in the membrane in order to fulfill its role as electron donor for diverse anchored enzymes. New insights into these and other aspects of heme and cytochromes functions would shed light into vital biological processes from these protozoan organisms that could be potential therapeutic targets.

\section{Acknowledgments}

J. A. Cricco and K. E. J. Tripodi are members of the carrier of scientific investigator of Consejo Nacional de Investigaciones Científicas y Técnicas, CONICET (Argentina). This study was partially supported by the CONICET (PIP2010 0685 GI to JAC).

\section{References}

[1] M. P. Barrett, R. J. S. Burchmore, A. Stich et al., "The trypanosomiases," Lancet, vol. 362, no. 9394, pp. 1469-1480, 2003.

[2] F. Bringaud, L. Rivière, and V. Coustou, "Energy metabolism of trypanosomatids: adaptation to available carbon sources," Molecular and Biochemical Parasitology, vol. 149, no. 1, pp. 19, 2006.

[3] L. Kořený, J. Lukeš, and M. Oborník, "Evolution of the haem synthetic pathway in kinetoplastid flagellates: an essential pathway that is not essential after all?" International Journal for Parasitology, vol. 40, no. 2, pp. 149-156, 2010.

[4] K. Furuyama, K. Kaneko, and P. D. Vargas, "Heme as a magnificient molecule with multiple missions: heme determines its own fate and governs cellular homeostasis," Tohoku Journal of Experimental Medicine, vol. 213, no. 1, pp. 1-16, 2007.

[5] S. W. Ryter and R. M. Tyrrell, "The heme synthesis and degradation pathways: role in oxidant sensitivity: heme oxygenase has both pro- and antioxidant properties," Free Radical Biology and Medicine, vol. 28, no. 2, pp. 289-309, 2000.

[6] C. T. Moraes, F. Diaz, and A. Barrientos, "Defects in the biosynthesis of mitochondrial heme $\mathrm{c}$ and heme a in yeast and mammals," Biochimica et Biophysica Acta, vol. 1659, no. 2-3, pp. 153-159, 2004.

[7] I. U. Heinemann, M. Jahn, and D. Jahn, "The biochemistry of heme biosynthesis," Archives of Biochemistry and Biophysics, vol. 474, no. 2, pp. 238-251, 2008.

[8] Y. Awa, N. Iwai, T. Ueda et al., "Isolation of a new antibiotic, alaremycin, structurally related to 5-aminolevulinic acid from Streptomyces sp. A012304," Bioscience, Biotechnology and Biochemistry, vol. 69, no. 9, pp. 1721-1725, 2005.

[9] G. Padmanaban and P. N. Rangarajan, "Heme metabolism of plasmodium is a major antimalarial target," Biochemical and Biophysical Research Communications, vol. 268, no. 3, pp. 665668, 2000.

[10] A. U. Rao, L. K. Carta, E. Lesuisse, and I. Hamza, "Lack of heme synthesis in a free-living eukaryote," Proceedings of the National Academy of Sciences of the United States of America, vol. 102, no. 12, pp. 4270-4275, 2005. 
[11] G. Padmanaban, V. A. Nagaraj, and P. N. Rangarajan, "An alternative model for heme biosynthesis in the malarial parasite," Trends in Biochemical Sciences, vol. 32, no. 10, pp. 443-449, 2007.

[12] H. A. E. Dailey, Biosynthesis of Heme and Chlorophylls, McGraw-Hill, New York, NY, USA, 1990.

[13] A. E. Medlockm and H. A. Dailey, "Tetrapyrroles," in Tetrapyrroles: Birth, Life and Death, M. J. Warren and A. G. Smith, Eds., pp. 116-127, Landes Bioscience, Austin, Tex, USA, 2007.

[14] S. Sato, B. Clough, L. Coates, and R. J. M. Wilson, "Enzymes for heme biosynthesis are found in both the mitochondrion and plastid of the malaria parasite Plasmodium falciparum," Protist, vol. 155, no. 1, pp. 117-125, 2004.

[15] V. A. Nagaraj, D. Prasad, P. N. Rangarajan, and G. Padmanaban, "Mitochondrial localization of functional ferrochelatase from Plasmodium falciparum," Molecular and Biochemical Parasitology, vol. 168, no. 1, pp. 109-112, 2009.

[16] P. Ponka, "Cell biology of heme," American Journal of the Medical Sciences, vol. 318, no. 4, pp. 241-256, 1999.

[17] C. Buchensky, P. Almirón, B. S. Mantilla, A. M. Silber, and J. A. Cricco, "The Trypanosoma cruzi proteins TcCox10 and TcCox15 catalyze the formation of heme A in the yeast Saccharomyces cerevisiae," FEMS Microbiology Letters, vol. 312, no. 2, pp. 133-141, 2010.

[18] T. M. Embley, M. Van Der Giezen, D. S. Horner et al., "Mitochondria and hydrogenosomes are two forms of the same fundamental organelle," Philosophical Transactions of the Royal Society B, vol. 358, no. 1429, pp. 191-203, 2003.

[19] T. M. Embley, "Multiple secondary origins of the anaerobic lifestyle in eukaryotes," Philosophical Transactions of the Royal Society B, vol. 361, no. 1470, pp. 1055-1067, 2006.

[20] G. R. C. Braz, H. S. L. Coelho, H. Masuda, and P. L. Oliveira, "A missing metabolic pathway in the cattle tick Boophilus microplus," Current Biology, vol. 9, no. 13, pp. 703-706, 1999.

[21] E. Ghedin, S. Wang, D. Spiro et al., "Draft genome of the filarial nematode parasite Brugia malayi," Science, vol. 317, no. 5845, pp. 1756-1760, 2007.

[22] F. A. Lara, U. Lins, G. Paiva-Silva et al., "A new intracellular pathway of haem detoxification in the midgut of the cattle tick Boophilus microplus: Aggregation inside a specialized organelle, the hemosome," Journal of Experimental Biology, vol. 206, no. 10, pp. 1707-1715, 2003.

[23] F. A. Lara, U. Lins, G. H. Bechara, and P. L. Oliveira, "Tracing heme in a living cell: hemoglobin degradation and heme traffic in digest cells of the cattle tick Boophilus microplus," Journal of Experimental Biology, vol. 208, no. 16, pp. 3093-3101, 2005.

[24] T. A. Salzman, A. M. Stella, E. A. Wider de Xifra, A. M. D. C. Batlle, R. Docampo, and A. O. M. Stoppani, "Porphyrin biosynthesis in parasitic hemoflagellates: Functional and defective enzymes in Trypanosoma cruzi," Comparative Biochemistry and Physiology, Part B, vol. 72, no. 4, pp. 663667, 1982.

[25] M. E. Lombardo, L. S. Araujo, and A. Batlle, "5Aminolevulinic acid synthesis in epimastigotes of Trypanosoma cruzi," International Journal of Biochemistry and Cell Biology, vol. 35, no. 8, pp. 1263-1271, 2003.

[26] M. Berriman, E. Ghedin, C. Hertz-Fowler et al., "The genome of the African trypanosome Trypanosoma brucei," Science, vol. 309, no. 5733, pp. 416-422, 2005.

[27] N. M. El-Sayed, P. J. Myler, D. C. Bartholomeu et al., "The genome sequence of Trypanosoma cruzi, etiologic agent of chagas disease," Science, vol. 309, no. 5733, pp. 409-415, 2005.
[28] M. Aslett, C. Aurrecoechea, M. Berriman et al., "TriTrypDB: a functional genomic resource for the Trypanosomatidae," Nucleic Acids Research, vol. 38, no. 1, pp. D457-D462, 2009.

[29] K. P. Chang and W. Trager, "Nutritional significance of symbiotic bacteria in two species of hemoflagellates," Science, vol. 183, no. 4124, pp. 531-532, 1974.

[30] K. P. Chang, C. S. Chang, and S. Sassa, "Heme biosynthesis in bacterium protozoon symbioses: enzymic defects in host hemoflagellates and complemental role of their intracellular symbiotes," Proceedings of the National Academy of Sciences of the United States of America, vol. 72, no. 8, pp. 2979-2983, 1975.

[31] J. F. Sah, H. Ito, B. K. Kolli, D. A. Peterson, S. Sassa, and K. P. Chang, "Genetic rescue of Leishmania deficiency in porphyrin biosynthesis creates mutants suitable for analysis of cellular events in uroporphyria and for photodynamic therapy," Journal of Biological Chemistry, vol. 277, no. 17, pp. 14902-14909, 2002.

[32] O. E. Akilov, S. Kosaka, K. O'riordan, and T. Hasan, "Parasiticidal effect of $\delta$-aminolevulinic acid-based photodynamic therapy for cutaneous leishmaniasis is indirect and mediated through the killing of the host cells," Experimental Dermatology, vol. 16, no. 8, pp. 651-660, 2007.

[33] S. Dutta, K. Furuyama, S. Sassa, and K.-P. Chang, "Leishmania spp.: delta-aminolevulinate-inducible neogenesis of porphyria by genetic complementation of incomplete heme biosynthesis pathway," Experimental Parasitology, vol. 118, no. 4, pp. 629-636, 2008.

[34] A. C. Ivens, C. S. Peacock, E. A. Worthey et al., "The genome of the kinetoplastid parasite, Leishmania major," Science, vol. 309, no. 5733, pp. 436-442, 2005.

[35] S. Severance and I. Hamza, "Trafficking of heme and porphyrins in metazoa," Chemical Reviews, vol. 109, no. 10, pp. 4596-4616, 2009.

[36] A. D. Uttaro, "Biosynthesis of polyunsaturated fatty acids in lower eukaryotes," IUBMB Life, vol. 58, no. 10, pp. 563-571, 2006.

[37] B. M. Joubert, L. N. Nguyen, S. P. T. Matsuda, and F. S. Buckner, "Cloning and functional characterization of a Trypanosoma brucei lanosterol $14 \alpha$-demethylase gene," Molecular and Biochemical Parasitology, vol. 117, no. 1, pp. 115-117, 2001.

[38] F. S. Buckner, B. M. Joubert, S. M. Boyle, R. T. Eastman, C. L. M. J. Verlinde, and S. P. T. Matsuda, "Cloning and analysis of Trypanosoma cruzi lanosterol 14 $\alpha$-demethylase," Molecular and Biochemical Parasitology, vol. 132, no. 2, pp. 75-81, 2003.

[39] K. E. J. Tripodi, L. V. Buttigliero, S. G. Altabe, and A. D. Uttaro, "Functional characterization of front-end desaturases from trypanosomatids depicts the first polyunsaturated fatty acid biosynthetic pathway from a parasitic protozoan," FEBS Journal, vol. 273, no. 2, pp. 271-280, 2006.

[40] V. I. Livore, K. E. J. Tripodi, and A. D. Uttaro, "Elongation of polyunsaturated fatty acids in trypanosomatids," FEBS Journal, vol. 274, no. 1, pp. 264-274, 2007.

[41] J. B. Schenkman and I. Jansson, "The many roles of cytochrome b," Pharmacology and Therapeutics, vol. 97, no. 2, pp. 139-152, 2003.

[42] M. A. Thiede, J. Ozols, and P. Strittmatter, "Construction and sequence of cDNA for rat liver stearyl coenzyme A desaturase," Journal of Biological Chemistry, vol. 261, no. 28, pp. 13230-13235, 1986.

[43] J. A. Napier, O. Sayanova, P. Sperling, and E. Heinz, "A growing family of cytochrome b-domain fusion proteins," Trends in Plant Science, vol. 4, no. 1, pp. 2-4, 1999. 
[44] A. G. Mitchell and C. E. Martin, "A novel cytochrome b-like domain is linked to the carboxyl terminus of the Saccharomyces cerevisiae $\Delta-9$ fatty acid desaturase," Journal of Biological Chemistry, vol. 270, no. 50, pp. 29766-29772, 1995.

[45] J. A. Napier, O. Sayanova, A. K. Stobart, and P. R. Shewry, "A new class of cytochrome b5 fusion proteins," The Biochemical Journal, vol. 328, pp. 717-718, 1997.

[46] W. C. Man, M. Miyazaki, K. Chu, and J. M. Ntambi, "Membrane topology of mouse stearoyl-CoA desaturase," Journal of Biological Chemistry, vol. 281, no. 2, pp. 1251-1260, 2006.

[47] A. R. Diaz, M. C. Mansilla, A. J. Vila, and D. De Mendoza, "Membrane topology of the acyl-lipid desaturase from Bacillus subtilis," Journal of Biological Chemistry, vol. 277, no. 50, pp. 48099-48106, 2002.

[48] A. Alloatti and A. D. Uttaro, "Highly specific methyl-end fatty-acid desaturases of trypanosomatids," Molecular and Biochemical Parasitology, vol. 175, no. 2, pp. 126-132, 2011.

[49] A. Alloatti, S. Gupta, M. Gualdrón-López et al., "Genetic and chemical evaluation of Trypanosoma brucei oleate desaturase as a candidate drug target," PLoS One, vol. 5, no. 12, Article ID e14239, 2010.

[50] C. K. Chen, S. S. F. Leung, C. Guilbert, M. P. Jacobson, J. H. Mckerrow, and L. M. Podust, "Structural characterization of CYP51 from Trypanosoma cruzi and Trypanosoma brucei bound to the antifungal drugs posaconazole and fluconazole," PLoS Neglected Tropical Diseases, vol. 4, no. 4, article e651, 2010.

[51] L. M. Podust, J. P. Von Kries, A. N. Eddine et al., "Smallmolecule scaffolds for CYP51 inhibitors identified by highthroughput screening and defined by X-ray crystallography," Antimicrobial Agents and Chemotherapy, vol. 51, no. 11, pp. 3915-3923, 2007.

[52] W. de Souza, M. Attias, and J. C. F. Rodrigues, "Particularities of mitochondrial structure in parasitic protists (Apicomplexa and Kinetoplastida)," International Journal of Biochemistry and Cell Biology, vol. 41, no. 10, pp. 2069-2080, 2009.

[53] D. Stroebel, Y. Choquet, J. L. Popot, and D. Picot, "An atypical haem in the cytochrome bf complex," Nature, vol. 426, no. 6965, pp. 413-418, 2003.

[54] J. Yu and N. E. Le Brun, "Studies of the cytochrome subunits of menaquinone: cytochrome c reductase (bc complex) of Bacillus subtilis. Evidence for the covalent attachment of heme to the cytochrome b subunit," Journal of Biological Chemistry, vol. 273 , no. 15 , pp. 8860-8866, 1998.

[55] J. W. Priest and S. L. Hajduk, "Cytochrome c reductase purified from Crithidia fasciculata contains an atypical cytochrome $c_{1}$," Journal of Biological Chemistry, vol. 267, no. 28, pp. 20188-20195, 1992.

[56] J. W. A. Allen, M. L. Ginger, and S. J. Ferguson, "Maturation of the unusual single-cysteine (XXXCH) mitochondrial c-type cytochromes found in trypanosomatids must occur through a novel biogenesis pathway," Biochemical Journal, vol. 383, no. 3, pp. 537-542, 2004.

[57] R. G. Kranz, C. Richard-Fogal, J. S. Taylor, and E. R. Frawley, "Cytochrome c biogenesis: mechanisms for covalent modifications and trafficking of heme and for heme-iron redox control," Microbiology and Molecular Biology Reviews, vol. 73, no. 3, pp. 510-528, 2009.

[58] J. M. Stevens, O. Daltrop, J. W. A. Allen, and S. J. Ferguson, "C-type cytochrome formation: chemical and biological enigmas," Accounts of Chemical Research, vol. 37, no. 12, pp. 999-1007, 2004.
[59] L. Thöny-Meyer, "Biogenesis of respiratory cytochromes in bacteria," Microbiology and Molecular Biology Reviews, vol. 61, no. 3, pp. 337-376, 1997.

[60] O. Christensen, E. M. Harvat, L. Thöny-Meyer, S. J. Ferguson, and J. M. Stevens, "Loss of ATP hydrolysis activity by CcmAB results in loss of c-type cytochrome synthesis and incomplete processing of CcmE," FEBS Journal, vol. 274, no. 9, pp. 2322-2332, 2007.

[61] R. E. Feissner, C. L. Richard-Fogal, E. R. Frawley, and R. G. Kranz, "ABC transporter-mediated release of a haem chaperone allows cytochrome c biogenesis," Molecular Microbiology, vol. 61, no. 1, pp. 219-231, 2006.

[62] S. J. Ferguson, J. M. Stevens, J. W. A. Allen, and I. B. Robertson, "Cytochrome c assembly: a tale of ever increasing variation and mystery?" Biochimica et Biophysica Acta, vol. 1777, no. 7-8, pp. 980-984, 2008.

[63] T. M. Embley and W. Martin, "Eukaryotic evolution, changes and challenges," Nature, vol. 440, no. 7084, pp. 623-630, 2006.

[64] R. E. Feissner, C. S. Beckett, J. A. Loughman, and R. G. Kranz, "Mutations in cytochrome assembly and periplasmic redox pathways in Bordetella pertussis," Journal of Bacteriology, vol. 187, no. 12, pp. 3941-3949, 2005.

[65] D. G. Bernard, S. T. Gabilly, G. Dujardin, S. Merchant, and P. P. Hamel, "Overlapping specificities of the mitochondrial cytochrome c and $c_{1}$ heme lyases," Journal of Biological Chemistry, vol. 278, no. 50, pp. 49732-49742, 2003.

[66] G. Kurisu, H. Zhang, J. L. Smith, and W. A. Cramer, "Structure of the cytochrome b6f complex of oxygenic photosynthesis: tuning the cavity," Science, vol. 302, no. 5647, pp. 1009-1014, 2003.

[67] J. W. A. Allen, A. P. Jackson, D. J. Rigden, A. C. Willis, S. J. Ferguson, and M. L. Ginger, "Order within a mosaic distribution of mitochondrial c-type cytochrome biogenesis systems?” FEBS Journal, vol. 275, no. 10, pp. 2385-2402, 2008.

[68] V. Fülöp, K. A. Sam, S. J. Ferguson, M. L. Ginger, and J. W. A. Allen, "Structure of a trypanosomatid mitochondrial cytochrome $\mathrm{c}$ with heme attached via only one thioether bond and implications for the substrate recognition requirements of heme lyase," FEBS Journal, vol. 276, no. 10, pp. 2822-2832, 2009.

[69] M. H. Barros and A. Tzagoloff, "Regulation of the heme A biosynthetic pathway in Saccharomyces cerevisiae," FEBS Letters, vol. 516, no. 1-3, pp. 119-123, 2002.

[70] D. M. Glerum and A. Tzagoloff, "Isolation of a human cDNA for heme A:farnesyltransferase by functional complementation of a yeast cox10 mutant," Proceedings of the National Academy of Sciences of the United States of America, vol. 91, no. 18, pp. 8452-8456, 1994.

[71] D. M. Glerum, I. Muroff, C. Jin, and A. Tzagoloff, "COX15 codes for a mitochondrial protein essential for the assembly of yeast cytochrome oxidase," Journal of Biological Chemistry, vol. 272, no. 30, pp. 19088-19094, 1997.

[72] A. Barrientos, M. H. Barros, I. Valnot, A. Rötig, P. Rustin, and A. Tzagoloff, "Cytochrome oxidase in health and disease," Gene, vol. 286, no. 1, pp. 53-63, 2002.

[73] H. Antonicka, S. C. Leary, G. H. Guercin et al., "Mutations in COX10 result in a defect in mitochondrial heme $\mathrm{A}$ biosynthesis and account for multiple, early-onset clinical phenotypes associated with isolated COX deficiency," Human Molecular Genetics, vol. 12, no. 20, pp. 2693-2702, 2003.

[74] B. E. Dwyer, M. L. Stone, N. Gorman et al., "Heme-a, the heme prosthetic group of cytochrome c oxidase, is increased in Alzheimer's disease," Neuroscience Letters, vol. 461, no. 3, pp. 302-305, 2009. 
[75] M. Vitali, E. Venturelli, D. Galimberti, L. Benerini Gatta, E. Scarpini, and D. Finazzi, "Analysis of the genes coding for subunit 10 and 15 of cytochrome c oxidase in Alzheimer's disease," Journal of Neural Transmission, vol. 116, no. 12, pp. 1635-1641, 2009.

[76] M. Chaudhuri, R. D. Ott, and G. C. Hill, "Trypanosome alternative oxidase: from molecule to function," Trends in Parasitology, vol. 22, no. 10, pp. 484-491, 2006.

[77] F. R. Opperdoes and P. A. M. Michels, "Complex I of Trypanosomatidae: does it exist?" Trends in Parasitology, vol. 24, no. 7, pp. 310-317, 2008.

[78] J. César Carranza, A. J. Kowaltowski, M. A. G. Mendonça, T. C. De Oliveira, F. R. Gadelha, and B. Zingales, "Mitochondrial bioenergetics and redox state are unaltered in trypanosoma cruzi isolates with compromised mitochondrial complex i subunit genes," Journal of Bioenergetics and Biomembranes, vol. 41, no. 3, pp. 299-308, 2009.

[79] J. Affranchino, M. N. Schwarcz De Tarlovsky, and A. O. M. Stopanni, "Terminal oxidases in the trypanosomatid Trypanosoma cruzi," Comparative Biochemistry and Physiology, Part B, vol. 85, no. 2, pp. 381-388, 1986.

[80] M. Ferella, D. Nilsson, H. Darban et al., "Proteomics in Trypanosoma cruzi-localization of novel proteins to various organelles," Proteomics, vol. 8, no. 13, pp. 2735-2749, 2008.

[81] A. Parodi-Talice, V. Monteiro-Goes, N. Arrambide et al., "Proteomic analysis of metacyclic trypomastigotes undergoing Trypanosoma cruzi metacyclogenesis," Journal of Mass Spectrometry, vol. 42, no. 11, pp. 1422-1432, 2007.

[82] T. Häusler, Y. D. Stierhof, J. Blattner, and C. Clayton, "Consevation of mitochondrial targeting sequence function in mitochondrial and hydrogenosomal proteins from the early-branching eukaryotes Crithidia, Trypanosoma and Trichomonas," European Journal of Cell Biology, vol. 73, no. 3, pp. 240-251, 1997. 

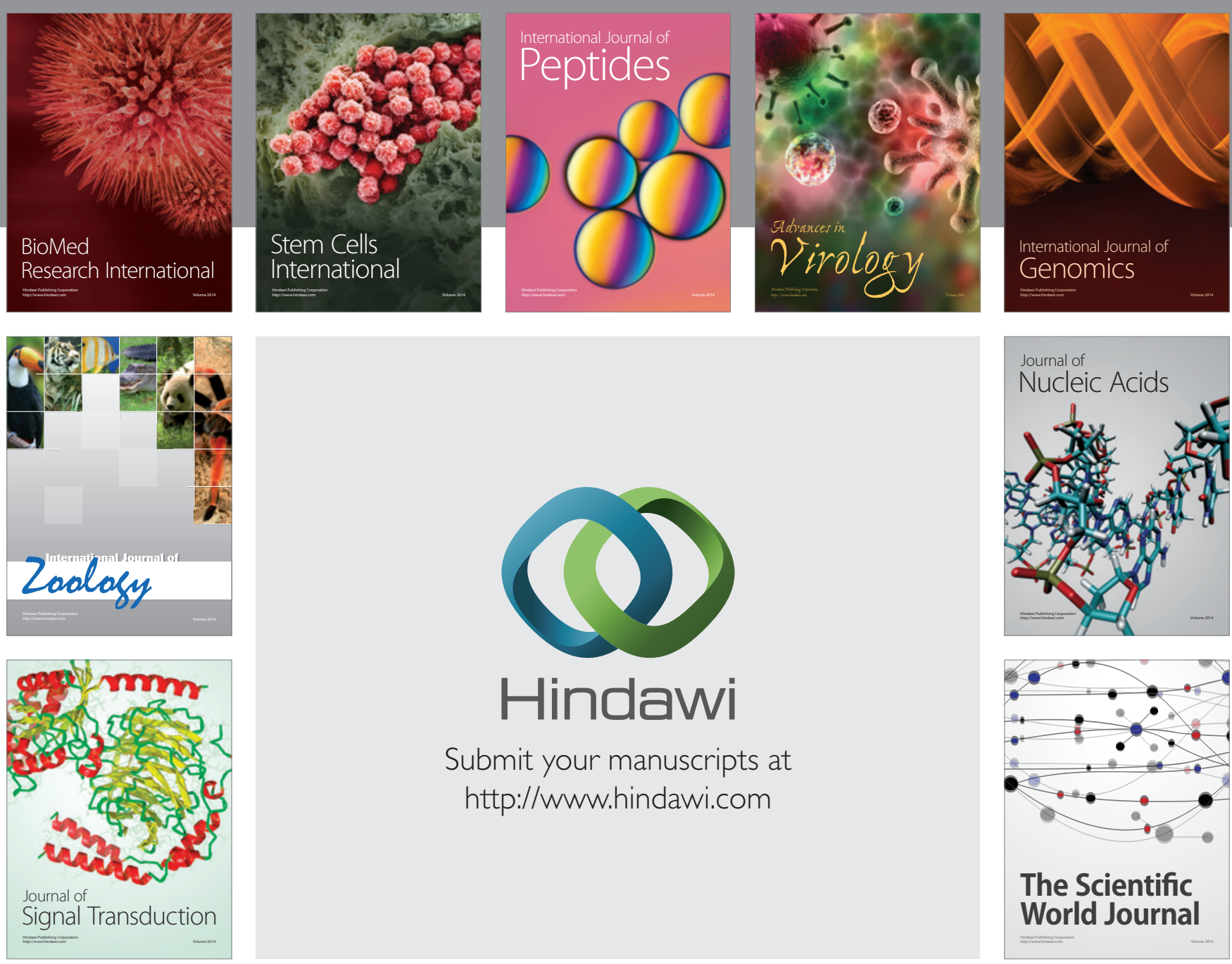

Submit your manuscripts at

http://www.hindawi.com
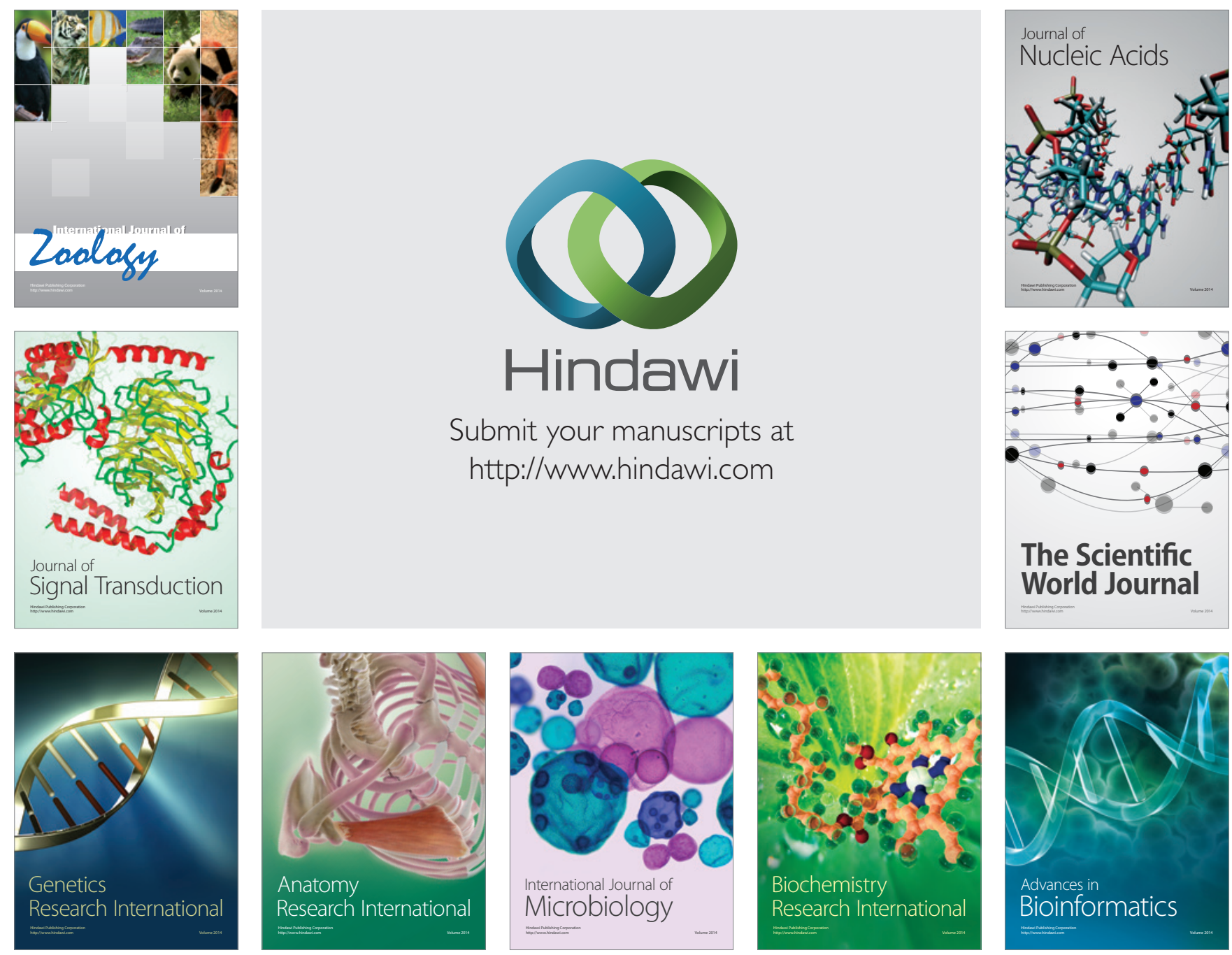

The Scientific World Journal
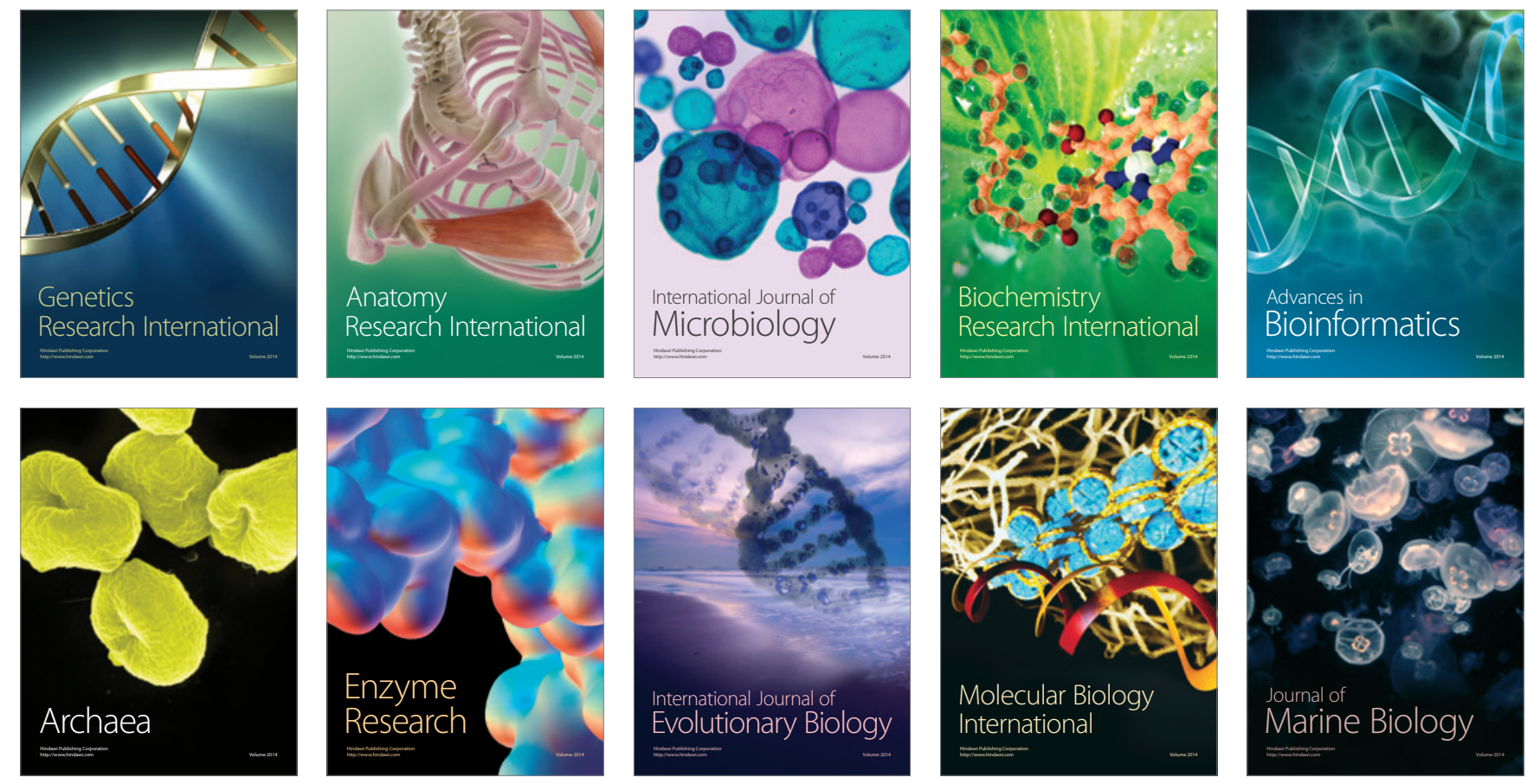